\title{
Uma Experiência Estética e didática sobre ciência e tecnologia por meio da literatura
}

| ${ }^{1}$ Marlon Ribeiro Silva, ${ }^{2}$ Paulo Schor, ${ }^{3}$ Dante Marcelo Gallian I

Resumo: Introdução: Discutimos o Potencial Estético-

Formativo da Literatura para uma Critica Estética da tecnologia em seus diversos âmbitos entre estudante dos cursos superiores em Tecnologia em Saúde da UNIFESP.

Objetivos: Verificar o potencial estético da literatura para pensar a tecnologia. Metodologia: Leitura de clássicos da literatura universal por meio da Metodologia do Laboratório de Humanidades e Tecnologia, atividade complementar oferecida aos estudantes dos cursos de tecnologia em saúde da UNIFESP. Para coleta dos dados usamos da Observação Participante e História Oral de Vida. Análise fundamentada na Fenomenologia Hermenêutica. Resultados: Com base em uma compreensão Estética da formação da Racionalidade humana, nossa atividade parece ser capaz de promover a análise crítica da tecnologia sob diversos âmbitos, tanto conceituais quanto para uma prática social e produtiva.

Conclusáo: Sugerimos a metodologia do LabHumTec como meio de possibilitar uma formação estética e humanística para produção e inovação tecnológica.

> Palavras-chave: Filosofia Estética. Filosofia da Tecnologia. Humanidades. Educação cientifica. Literatura.

\author{
${ }^{1}$ Universidade Federal de São \\ Paulo. São Paulo-SP, Brasil \\ (marlon.educ@gmail.com).ORCID: \\ 0000-0003-4286-2496 \\ ${ }^{2}$ Universidade Federal de São \\ Paulo. São Paulo-SP, Brasil \\ (pschor@pobox.com). ORCID: \\ 0000-0002-3999-4706 \\ ${ }^{3}$ Universidade Federal de São \\ Paulo. São Paulo-SP, Brasil (dante. \\ cehfi@epm.br). ORCID: 0000- \\ 0002-5452-215X
}

Recebido em: 31/10/2019 Aprovado em: 22/05/2020 Revisado em: 13/10/2021 


\section{Introdução}

\section{A Literatura Clássica e a Problematização da Tecnologia}

"Como ousas brincar assim com a vida?" (SHELLEY, 2001, p. 115), perguntou a criatura de Victor Frankenstein ao seu criador diante do asco revelado por este frente a sua criação. A táo conhecida história de Mary Shelley tem muito a nos dizer sobre o imaginário moderno quanto às possibilidades e os riscos da ciência e da tecnologia. Na história, o nobre doutor, levado pelo apogeu do espirito cientifico de seu tempo, tinha a inquietação de resolver o problema da morte, como afirma: "A saúde era um assunto vulgar, mas que glória não envolveria a descoberta se eu pudesse banir para sempre a doença do ser humano e tornasse o homem imune a tudo que não fosse a morte violenta" (SHELLEY, 2001, p. 45).

Podemos ver, em diversas obras literárias, o imaginário a respeito do axioma humano frente à existência, resultado da racionalidade promovida pela técnica. Portanto, essas obras podem representar mais do que mero entretenimento, antes, proporcionar profundas reflexóes filosóficas sobre a influência da ciência e da tecnologia sobre a cultura e a existência humana (SILVA; GALLIAN; SCHOR. 2016). Neste sentido, para focar no que é de interesse deste artigo, iremos tratar da relação entre literatura, ciência e tecnologia, com base em uma experiência didática com alunos de graduação dos cursos de Radiologia, Informática em Saúde e Tecnologia Oftálmica da UNIFESP. Não apenas com relação ao processo produtivo em si, antes, no sentido atribuído; não somente ao produto ou conhecimento, mas, principalmente, quanto ao seu potencial estético, ou seja, formativo.

Tendo em vista que alguns podem considerar ousado o debate crítico que será levantado, precisamos nos situar filosoficamente e discutir uma questão antiga, mas a qual se dá muita pouca atenção, a saber, a relação entre arte, ciência, tecnologia e a nossa formação intelectual.

A respeito disso, Bruno Latour nos diz que:

Nossa vida intelectual é decididamente mal construída. A epistemologia, as ciências sociais, as ciências do exato, todas têm uma reputação, contanto que permaneçam distintas. Caso os seres que você esteja seguindo atravessem as três, ninguém mais compreende o que você diz. Ofereça às disciplinas estabelecidas uma bela rede sócio-técnica, algumas belas traduções, e as primeiras extrairão os conceitos, arrancando deles todas as raízes que poderiam liga-los ao social ou à retórica; as segundas irão amputar a dimensão social e política, purificando-a de qualquer objeto; as terceiras, enfim, conservarão o discurso, mas irão purga-lo de qualquer aderência indevida à realidade - horresco referens - e aos 
jogos de poder. O buraco de ozônio sobre nossas cabeças, a lei moral em nosso coração e o texto autônomo podem, em separado, interessar a nossos críticos. Mas se uma naveta fina houver interligado o céu, a indústria e os textos, as almas e a lei moral, isto permanecerá inaudito, indevido, inusitado (LATOUR, 1994. p. 11).

Além disso, quando alguém tenta superar essas barreiras, se torna incompreendido. O que representa uma limitação formativa e intelectual. Essas barreiras separam conhecimentos que, tratados como distintos, não apenas perdem seu sentido de ser como prejudicam tanto a compreensão do próprio fazer quanto sua qualidade. Como nos diz Bronowski (1979): “[...] devemos temer sempre que ouvimos um homem de sensibilidade considerar a ciência como assunto que pertence à outra pessoa" (p. 12). Tanto quanto "Quando os homens não compreendem o seu próprio trabalho, não podem compreender o trabalho dos outros; de modo que é natural que estes cientistas tenham sentido indiferença pelas artes" (p. 13). Logo, ao entender que existe uma separação entre tais saberes, queremos dizer, à priori, que esta deve ser superada.

O potencial estético formativo da arte diz respeito à forma como esta pode influenciar, em nossa racionalidade, a forma como nos entendemos no mundo e atuamos nele, sendo assim "[...] um ideal de cultura que é também expressão de um anseio de mudanças ao nível da estrutura sociopolítica” (PEQUITO, 1996, p. 192).

Desta forma, entendemos por estética a força potencial da arte em ampliar nossas perspectivas emocionais e racionais da realidade, podendo assim, promover um espaço de livre reflexão e liberdade. Com este fim, usamos como método de pesquisa o Laboratório de Humanidades e Tecnologia, descrito adiante.

\section{Caminho}

\section{Laboratório de Humanidades e Tecnologia}

O Laboratório de Humanidades e Tecnologia foi o caminho adotado para obter os dados apresentados neste trabalho, como uma experiência formativa. Tendo em vista que nossa atividade é uma extensão do Laboratório de Humanidades (LabHum), do Centro de História e Filosofia das Ciências da Saúde (CeHFi) da UNIFESP, precisamos contar um pouco de sua história e o que já foi produzido a respeito.

O Laboratório de Humanidades nasceu por iniciativa dos alunos da disciplina "História da Medicina", oferecida como atividade extracurricular pelo professor Dante Gallian, na Escola Paulista de Medicina, com a finalidade de discutir textos 
de história e filosofia. Com o passar do tempo e amadurecimento das discussôes e das ideias, deu-se a leitura de textos clássicos da literatura (GALLIAN, 2017).

Já como atividade de graduação e pós-graduação, o LabHum tem em sua agenda diversas turmas que se encontram semanalmente, hoje em dia não somente na UNIFESP, como em outros lugares e instituiçôes. Entretanto, na UNIFESP temos, dentre os participantes, graduandos da área da saúde, pós-graduandos, docentes, funcionários e pessoas de fora da UNIFESP. Tais turmas têm por objetivo, com base em uma metodologia estabelecida, discutir impressôes de leitura, compartilhar sentimentos, ideias e efeitos causados a partir da leitura, o que gera resultados não somente individuais, antes tem potencial de afetar a todos os que participam e compartilham a respeito de suas experiências.

De acordo com o desenvolvimento da leitura, muitas questóes surgem e uma diversidade de ideias e sensaçóes se soma às perspectivas dos outros participantes, gerando novas impressóes e processos dialéticos de assimilação e acomodação de novas informaçôes, que geram, por sua vez, crises e identificação em outros participantes. Configura-se, portanto, um ambiente de liberdade reflexiva, sem a necessidade de desenvolver teses sobre o texto, resultando em compartilhamento de saberes pessoais que enriquecem visóes de si mesmo, do outro e do mundo. A experiência comunal de leitura dos clássicos explora e aprofunda reflexôes a respeito de temas fundamentais para e existência humana de forma livre e afetuosa. Isto gera nos participantes uma liberdade maior para se expressarem. Além disso, essa diversidade de pontos de vistas afeta, por sua vez, os outros participantes (GALLIAN, 2012).

A metodologia do LabHum segue orientações básicas de organização. Os livros a serem lidos são sugeridos pelo coordenador antes do início das atividades acadêmicas. Geralmente são dois livros por semestre, seguindo uma sequência de cerca de sete encontros, em média, de discussóes sobre cada livro.

No primeiro encontro, a dinâmica da atividade é explicada pelo coordenador. Nesse encontro inicial, a fim de deixar os participantes cientes dos fundamentos e objetivos dos encontros, os participantes são apresentados a discussóes teóricas sobre a metodologia aplicada na atividade; assim como sua história e resultados de pesquisas realizadas (BITTAR, SOUSA, GALLIAN, 2012; GALLIAN, 2012; SILVA, GALLIAN, SCHOR, 2016; SILVA, GALLIAN, 2016; GALLIAN, 2017).

No segundo encontro, que chamamos de "histórias de leitura", o leitor expóe suas primeiras impressões, sensaçóes, sentimentos, etc. a respeito da leitura, ou seja, 
como foi a leitura. Esse encontro é fundamental como ponto de partida também de comparação entre o "antes e depois" das discussóes. A partir deste encontro começam a aparecer efetivamente os temas suscitados pela leitura, por hora, particular, e as impressôes divergentes começam a gerar novas perguntas entre os participantes. Esses temas indicarão o caminho a ser percorrido no que chamamos de "Itinerário de Discussão", onde os primeiros tópicos a serem tratados são postos ao debate.

Nos encontros de "Itinerário de Discussão", as perguntas fundamentais levantadas durante os debates sáo colocadas pelo coordenador no início de cada encontro. $\mathrm{O}$ número de encontros varia de acordo com o tamanho do livro entre outros fatores, como imprevistos na agenda docente, pessoal e da turma. $O$ papel fundamental do coordenador, neste caso, é organizar as perguntas a serem feitas, assim como moderar o debate, entretanto, sem deixar de ser também um participante. O que será elucidado melhor adiante.

Por fim, no último encontro de cada "ciclo", ou seja, ao fim da leitura de cada livro, ouvimos as "Histórias de Convivência", momento em que os participantes têm a oportunidade de falar a respeito de suas experiências particulares de convivência de leitura e discussão em grupo. Discute-se então, como, ou se, a convivência em grupo mudou, ou influenciou, de alguma forma, sua formação pessoal. Esse encontro é fundamental metodologicamente, pois a comparação dessas falas com as Histórias de Vida, da qual falarei adiante, não somente fortalecem a validade do discurso, como enriquecem quantitativamente e qualitativamente o material a ser analisado.

Os encontros realizados para fundamentação dessa pesquisa estão parcialmente transcritos. Os métodos de coleta e análise de dados estão descritos adiante.

Aos alunos dos cursos de tecnologia em saúde da UNIFESP, a atividade foi oferecida do primeiro semestre de 2015 ao primeiro semestre de 2016, onde foram lidos e discutidos, nesta ordem, seis livros, a saber: "Frankenstein", de Mary Shelley (2001); "1984", de George Orwell (1991); "Admirável Mundo Novo”, de Aldous Huxley (1982); Hamlet, de William Shakespeare (1981); A Máquina do Tempo, de H.G. Wells (2010); e "O Sonho de Um Homem Ridículo", de Fiódor Dostoiévski (2003).

É nesse ambiente que investigamos como a experiência do Laboratório de Humanidades e Tecnologia pôde ser considerada como um caminho de formação humanística entre estudantes dos cursos de graduação em tecnologias em saúde. 


\section{Observação Participante}

A coleta de dados é feita a partir de três métodos: Observação Participante (GEERTZ, 2009), entrevistas obtidas de acordo com a abordagem da História Oral de Vida (MEIHY; HOLANDA, 2007). A análise dos resultados é feita com base na Fenomenologia Hermenêutica (BORKAN, 1999).

Buscamos, inicialmente, nos ater à experiência coletiva antes da particular, pois em grupo a experiência pessoal pode ser extremamente enriquecida e adquirir significado e sentido. Por esse motivo, optamos pela Observação Participante como forma de alcançar essas falas e procurarmos observar o fenômeno em si, de forma tal que a fala dos envolvidos constituísse a fonte primária de produção de sentido. Como sugerido por Geertz:

\footnotetext{
"[...] trata-se de como introduzir um autor testemunha ocular numa história de retrato deles. Comprometer-se com uma concepção essencialmente biográfica do Estar Lá, em vez de uma concepção reflexiva, aventureira ou observacional, é comprometer-se com uma abordagem confessional da construção do texto". (GEERTZ, 2009, p. 112).
}

Todas as reunióes foram registradas por meio de gravador digital. Esses registros sonoros foram transcriados, parcialmente, para a análise, como apresentado na seção de impactos e reflexôes, em forma de diálogos.

\section{História Oral de Vida (HOV)}

Diante da necessidade do testemunho pessoal de determinados participantes para compreensão da experiência estética do LabHumTec, optamos pela investigação da fonte oral, por meio da História Oral de Vida (MEIHY; HOLANDA, 2007). Dessa forma, os participantes voluntários - colaboradores em se tratando desta abordagem - foram entrevistados e tiveram a oportunidade de expor suas experiências de forma mais profunda, relacionando tais experiências a outras esferas de suas vidas. Isso nos proporcionará uma visão mais abrangente do ocorrido.

Dos nove participantes regulares da atividade, oito foram entrevistados, considerando que uma das alunas náo quis colaborar com a entrevista.

As seguintes etapas são seguidas para o completo cumprimento metodológico da HOV:

- Entrevista: os colaboradores que aceitaram ser entrevistados após terem sido inteirados acerca do projeto de pesquisa e da metodologia da História Oral de vida, assinaram o Termo de Consentimento Livre e Esclarecido (TCLE), de acordo 
com as exigências do Comitê de Ética e Pesquisa da universidade, pela Plataforma Brasil, sob o parecer 554.224, de 12/03/2014.

- Transcriçáo: ocasião em que as entrevistas são transcritas integralmente.

- Textualizaçáa: processo intermediário entre a transcrição e a transcriação, em que o texto começa a tomar forma de discurso em primeira pessoa e as falas dos colaboradores passam a ser elemento único no texto.

- Transcriação: momento metodológico mais importante em História Oral, pois "a transcriação nos aproxima do sentido e da intenção original que o colaborador quer comunicar” (MEIHY; HOLANDA, 2007, p. 135). Na transcriação, a entrevista passa a ser definitivamente somente a fala do colaborador, transformando-se em uma narrativa pessoal. É um "[...] ato de recriaçáo para comunicar melhor o sentido e a intenção do que foi registrado" (MEIHY; HOLANDA, 2007, p. 136).

- Conferência e aprovaçáo do texto final: após a redação do texto transcriado, os textos seráo enviados para os colaboradores para serem conferidos e revistos e, finalmente, aprovados pelo colaborador. Este será informado de ter completa autonomia para alterar ou sugerir mudanças no texto caso houvesse informaçôes que não desejasse expor ou que de fato não fossem coerentes com seus interesses e intenções.

- Devolução: momento em que, após as devidas correçôes, o colaborador receberá novamente o texto. Após as conferências por parte dos colabores estarem concluídas, serão solicitadas as assinaturas da documentação pertinente à parte ética da pesquisa.

\section{Interpretação de Dados}

Os textos produzidos foram interpretados por meio do estilo de organizaçáo denominado imersão/cristalização, o qual é inspirado na Fenomenologia Hermenêutica (BORKAN, 1999). No processo de imersão examinamos alguns dos dados detalhadamente. A cristalização é o processo de suspender o exame dos dados a fim de identificar e articular padróes ou temas observados durante a imersão. De acordo com a concepçáo interpretativa-hermenêutica, analisamos os dados fragmentando e reorganizando os fragmentos. As falas dos colaboradores são, assim, divididas de forma a possibilitar um procedimento minucioso de interpretação de seus significados, articulando-as entre si para poder formular hipóteses explicativas do universo estudado (DUARTE, 2004). Assim, a partir da análise profunda e 
exaustiva das falas resultantes dos métodos de coleta, buscamos responder à questão fundamental deste estudo, ou seja, se a experiência da literatura pode ou não gerar reflexão crítica quanto à ciência e tecnologia, à luz da experiência pessoal com foco na dimensão da afetividade.

\section{Impactos e reflexóes}

Nossa análise está focada na complexidade da discussão dos textos sugeridos para a atividade e nas histórias de vida, tendo como base fundamental a fala dos participantes.

As citaçôes referentes às transcrições dos encontros serão referenciadas com o pseudônimo e curso do colaborador: Carmen - Informática em Saúde; Jean Radiologia; Bruce - Tecnologia Oftálmica; Fabiana - Tecnologia Oftálmica; Sakura - Radiologia; Alonso - Informática em Saúde; Nikolai - Informática em Saúde e Naoko - Informática em Saúde.

\section{O Sentimento no Processo de Criação}

Começaremos discutindo como nossa atividade promoveu um debate crítico a respeito do sentimento no processo criativo/produtivo. No ciclo onde discutimos "Frankenstein", o debate aparece de forma profundamente ligada à história. Podemos observar que o mesmo gira em torno dos sentimentos do personagem Victor Frankenstein em seu processo criativo, como segue:

"Nikolai: Mas eu estranhei na hora que ele termina o monstro porque ele passa da excitação para o arrependimento. Ele cria a vida e já pega nojo.

Alonso: Ele se ilude, né? Se deixa cegar.

Nikolai: É o que dá a entender, né? Tipo. Quando ele está no processo criativo já demonstra angústia, como ele está se deteriorando. Mas mesmo assim ele demonstra a excitação.

Alonso: É que ele se apaixonou tanto pela complexidade do corpo humano que ele falou assim: "não é possível que isso aqui acabe tão rápido". Uma coisa tão perfeita, tão bonita, mas acaba e vai parar de baixo da terra, vai para os vermes. Talvez ele não se conforme. "Então eu quero tentar prolongar isso o máximo possível para evitar esse fim".

Primeiro notamos uma relação entre excitação e arrependimento, compreendida, no final, com a colaboração de Alonso, que essa excitação partia de uma vontade nobre, a de preservar a beleza da vida humana. Entretanto, logo essa excitação se transforma em arrependimento quando a criatura, finalmente torna-se viva. Pouco adiante, continua Alonso: 


\begin{abstract}
"Eu senti que ele percebe que o negócio que ele está criando não vai dar tão certo quanto ele achava. Não vai ser perfeito. Dá a impressão que talvez ele achasse que não ia dar certo nunca. Até por ele já conhecer a estrutura do corpo, ia ser muito complicado. Parece que ele já está se arrependendo, mas ele está tão cego pela empolgação de brincar de Deus que ele não consegue. Até que, realmente, na hora que vem esse estalo, esse raio, aí ele olha e fala: “Meu...”. Não dá tempo de falar: "Não, funciona”. Ele já pensou outra coisa. Lascou, e fugiu, surtou".
\end{abstract}

Agora, uma pergunta aparece: Porque Victor continuou mesmo sabendo que resultaria em algo ruim? Neste sentido, a paixão que gera a vontade de, pelo conhecimento, tentar realizar algo aparentemente nobre, como buscar a eternidade da vida, acaba resultando em um arrependimento, mas por quê? Continuemos a observar o debate:

"Nikolai: É. Porque dá aquela impressão de que talvez ele estivesse tão imerso no processo de criação que ele só se dá conta quando acaba, né? Só então ele consegue abrir os próprios olhos. Quando a criatura abre os olhos. Ele descreve: "foi uma noite sombria, de novembro, que contemplei a realização da minha obra”. [...] Talvez seja até o foco do livro. Em boa parte, pelo menos a primeira parte do livro, parece ser o foco. Essa descriçáo dos sentimentos e da experiência própria do personagem".

\title{
Pouco depois, Alonso acrescenta:
}

"É foda, porque assim. O que eu fiquei pensando também, quando estava lendo isso aqui, foi que o Victor, ao mesmo tempo em que esperava ver a criatura, ele náo queria ver a criatura de novo. Ele ficava rodando, forçando uma situação. Acreditou que não mais o veria e, de repente, ele aparece falando "você me acompanha, você tem que me ouvir agora. O mínimo que você tem que fazer como meu criado é me ouvir”. A gente, no papel do criador em choque, vendo uma criatura da qual você saiu correndo e de repente ela falando com você, conversando de forma pautada, com sentimento, com nível de consciência com algumas questóes que nem ele próprio, talvez, pensaria daquela forma. "O que eu faço com isso aqui"? O choque.... É aprendizado? É sentimento? É você poder mudar o sentimento rapidamente? Uma coisa que um robô ainda náo pode, consegue, de forma efetiva? É, grande criador. O grande criador não o guia nesse primeiro momento de reflexão e aprendizado, foi a natureza. Ele anda durante a noite, vê, olha para as formas, para as árvores".

Agora entram em cena novos sentimentos a serem compreendidos. Se Victor se arrependeu do que havia feito apenas após ver o resultado real de sua criação e ter se assustado, e, mesmo já se arrependendo durante o processo, tendo continuado em função da cegueira advinda da arrogância e da vontade, conclui se perguntando que sentimento é esse gerado nessa relação de recusa por parte de seu criador para com sua criatura. O que se faz com isso? É aprendizado? Se o criador abandona sua criatura e 
não a guia nos primeiros momentos, sua criatura abandonada é responsabilidade de quem? Este debate, a partir de uma obra de fantasia, levanta uma questão ética em relação ao processo criativo a partir da discussão de sentimentos apresentados no texto como parte da narrativa.

Ainda seguindo uma ideia de uma ética no processo criativo, que passa pelos sentimentos, o que se coloca em questáo, fundamentalmente, é o interesse que fundamenta o desejo, tanto da obtenção de conhecimento quanto de sua realização em forma de tecnologia. Essa problematização trouxe, naturalmente, uma questão de cunho moral, como segue:

"Nikolai: Ele não se lamenta tanto. E esse fato, dele se esquecer dos seus motivos, que eu
acho que entra um pouco desse seu momento de tipo; "o que aconteceu”? Né? Essa refle-
xáo póstuma do ocorrido, fazendo uma analogia direta à própria criaçáo dele. Naquele
momento, onde o Victor estava criando a criatura, sem muito pensar a respeito e só depois
veio se dar conta do que ocorreu. É muito disso também. Esse processo de você estar
criando algo, estar táo absorto no seu trabalho que você não reflete mais sobre".

Nesta última fala percebemos uma conclusão fundamental a respeito da formação de um debate crítico oriundo de nossa atividade. Além dos pontos relacionados citados acima, agora chegamos ao ponto em que o sentimento atende um papel de formação de racionalidade. A conclusão é que Victor, a princípio, não lamenta tanto. Estando tão profundamente "absorto" em sua criação que, apenas após sua finalização, começa a refletir sobre isso. Ou seja, os sentimentos não o impedem de prosseguir com sua obra que já aparentemente gerará problema, mas outros sentimentos o fazem prosseguir. Apenas com o final da "realização" desses sentimentos, parece que a razão aparece.

No ciclo onde discutimos "Admirável Mundo Novo" (HUXLEY, 1982), outro debate nos parece relevante quanto ao tema que tratamos neste tópico, como segue:

"Nikolai: Bom, vou começar com uma frase que a gente já falou anteriormente, né? Acho que no nosso último encontro a gente usou essa frase e eu acho que a gente podia inclusive começar por ela a discussão. Que é... "Amar o que somos obrigados a fazer. ” É o segredo da felicidade (...) amar o que somos obrigados a fazer. A finalidade de todo condicionamento. Fazer as pessoas amarem o destino social de que não podem escapar."

Pouco adiante, o debate continua:

Nikolai: Acho bastante interessante. E comparando com a nossa realidade mesmo, é uma coisa que a gente já está trabalhando isso, né? Essa ideia de amar algo que você vai ter que fazer.

Naoko: Sim, bastante. 
Nikolai: A gente é menos programado para fazer isso.

Pergunta do coordenador: Somos menos programados?

Naoko: Não, na verdade eu acho que se você não se programa em determinadas situações, principalmente de trabalho, coisa assim. Se você não faz uma autoprogramação para você suportar isso, se torna a situaçáo insustentável.

Essa reflexão nos mostra o papel da razão no processo criativo por meio de sua compreensão estética. Um exemplo foi dado acima. No processo criativo de Victor, os sentimentos parecem terem operado antes da razão. Tendo em vista a concepção, já citada, de Schiller, a respeito do Impulso Lúdico (SCHILLER, 2009) que representa a unidade da razão e da sensibilidade, o que podemos colocar também como emoção, este chamado jogo, só se realiza na esfera estética. Assim, como superar essa separaçáo entre razão e sensação em um processo que, apesar de, à priori, se proclamar racional parece, antes, um processo fundamentado em sentimentos, em detrimento de sua mediação pela razoabilidade do pensamento.

Agora, diferente do sentimento em relação ao que se cria, o debate aparece no sentido do sentimento de ser o produtor, obviamente em um cenário de produção massiva. Entretanto, o ponto fundamental é a observaçáo a respeito de amar o que faz como forma de submissão.

No sentido da racionalidade e processo de produção, discutiremos os debates em torno da ideia de "consciência" no processo criativo.

\section{Responsabilidade e consciência no processo criativo e produtivo}

Continuando o debate de "Frankenstein", agora já tendo discutido a importância da relação entre sensação e razão, veremos como o debate sobre consciência, ou seja, sobre a razoabilidade, aparece no processo criativo/produtivo.

Neste sentido, Nikolai coloca:

"E mesmo assim ele não chega a refletir sobre a criação dele, né? Ele não dá essa impressão. Ou talvez já tenha refletido enquanto produzia. Mesmo assim, esse estado me causou um pouco de estranheza.

E ele também não pensa em outras aplicações. Tipo, a experiência é só aquela. Mas, e o conhecimento que o processo cria, né? É interessante que ele não tenta aplicar o conhecimento de nenhuma outra forma. Seria só aquele o único objetivo, o único mecanismo...”

A não reflexão de Victor a respeito do processo criativo ainda está associada à limitação do pensamento causada pelos sentimentos que o levou à "cegueira", 
como exposto em diálogo anterior. Outro fator interessante dessa irracionalidade no processo de criação é a falta de reflexão a respeito da complexidade do que se cria, ou seja; seu objeto tem apenas uma aplicação diretamente ligada a um único interesse. Este que não passa pelo crivo da razoabilidade?

Partindo deste debate, Alonso trás a questão da natureza, vinculando o criador à criatura, em relação, segundo Nikolai, à dominação da natureza, interesse implícito em Victor Frankenstein.

\footnotetext{
"Alonso: Talvez o criador e criatura tenham o mesmo vínculo. É esse gosto da natureza. Que é o tempo para criar e um tempo para tentar chamar a atenção, se preparar para poder encarar ele, né? A criatura encarar o criador.
}

Nikolai: Ele já demonstra um interesse de sobrepor a natureza. Se sobrepor na natureza, um domínio da natureza."

A partir do debate de "Frankenstein" também discutimos a questão da beleza da criação do ponto de vista da consciência. Neste exemplo, os participantes discutem o sentimento de repulsa pela criatura percebida como feia após realização do processo. E este sentimento estético em relação à sua criação aparece como sendo consequência da falta de racionalidade, como segue:

"Naoko: Até a criatura ter vida, era bela. Quando algo se torna vivo, perdemos o controle e então vem o medo. O monstro percebe mais a responsabilidade do Victor que o próprio criador. No processo de criação, Victor se desliga da sua humanidade. O monstro é um ser superior a ele. Em algum momento ele perde o afeto (o monstro). Qual o traço desumanizador da criatura? A estética. Ele se vê reprovável.

Chegamos ao fim deste debate com a ideia de uma criatura mais racional que o próprio criador, este que, não fazendo uso da razão, sob o controle emocional de interesses perturbados, não questiona a respeito das possíveis consequências de seus atos. Com medo, abandona sua criação, esta que desenvolve moral e razão de forma independente.

\section{Técnica e Estética em Discussão}

Com base nesses diálogos, frutos das discussôes dos livros propostos, sugerimos que a literatura pode proporcionar grande potencial de promoção e reflexão crítica e estética quanto a Ciência e a Tecnologia, em nosso caso, na área da saúde.

Quando falamos em potencial estético, nos referimos, seguindo a Filosofia Estética Schilleriana, ao papel da arte na formação do ser humano, onde: 
“[...] a complacência estética brota da forma que confiro à matéria recebida. Eu me deleito com o agradável porque isto me dá a oportunidade de sofrer algo; eu me deleito com o belo porque isto me dá a oportunidade de fazer algo" (SCHILLER, 2009, p. 116).

Aldous Huxley, em seu "Admirável Mundo Novo" (HUXLEY, 1982), nos mostra um possível mundo onde, aparentemente, a tecnologia resolveu problemas humanos; como o sofrimento e a dor. Mas com a presença do "Selvagem", muitas questôes profundas sobre a existência humana, que ultrapassam questóes técnicas, voltam a incomodar alguns personagens.

Como posto pelo filósofo alemão Jürgen Habermas:

“ [...] na mesma medida em que os problemas de ordem técnica são solucionados cientificamente, eles se transformam em tantos outros problemas de vida; pois os controles científicos dos processos sociais e naturais - em uma palavra: as tecnologias - não dispensam o homem da ação" (HABERMAS, 2014, p. 142).

Se as tecnologias não dispensam o "homem da açáo", devemos nos perguntar onde ele se localiza nesta relação.

Segundo Huxley;

"[...] la ciência puede definirse como una invención para investigar, ordenar y comunicar las más públicas de las experiencias humanas. De modo menos sistemático, la literatura también trata de estas experiencias públicas. Fundamentalmente le conciernen, sin embargo, las experiencias más privadas del hombre y la relacion recíproca entre los mundos privados del sentimento, los indivíduos auto-consciente y los universos públicos de la 'realidad objetiva', la lógica, las convenciones sociales y la información acumulada comúnmente asequible" (HUXLEY, s/d. p. 11).

Enquanto a literatura "[...] es una invencion para regitrar los hechis plurifacéticos y expressar sus varias significaciones” (HUXLEY, s/d. p. 20). Ou seja, Huxley está dizendo que a literatura tem maior potencial em comunicar os conhecimentos científicos, de forma mais ampla, pelo fato de ser uma linguagem intersubjetiva, ou como diz, plurifacética, ou seja, que com mais facilidade é compreensível para a maior parte das pessoas, "O homem da razão". Enquanto a ciência tem uma linguagem particular, mais facilmente compreendida pelos que a ela se dedicam. $\mathrm{O}$ conceito de estética, como de acordo com Rancière, também nos é relevante quanto à compreensão de que ações compartilhadas que produzem sentido e, portanto, tem potencial formativo, "O importante é ser neste nível, do recorte sensível do comum da comunidade, das formas de sua visibilidade e de sua disposição, que se coloca a questão da relação estético/política" (RANCIÈRE, 2009. p. 26). 
Nesta relação, a arte tem um papel fundamental tanto quanto meio de ampliação do pensamento crítico quanto de emancipação política. Entretanto, essa função se aplica de acordo com a subjetividade da "escrita" (RANCIÈRE, 2009. p. 20-21), pois:

"As artes nunca emprestam às manobras de dominação ou de emancipação mais do que lhes podem emprestar, ou seja, muito simplesmente, o que têm em comum com elas; posições e movimento dos corpos, funçóes da palavra, repartiçôes do visível e do invisível. E a autonomia de que podem gozar ou a subversão que podem se atribuir repousam sobre a mesma base" (RANCIÈRE, 2009. p. 26).

A partir deste conceito de Partilha do Sensível como uma atividade estética é que, segundo o filósofo francês:

“[...] se pode colocar a questão das 'praticas estéticas', no sentido em que entendemos, isto é, como forma de visibilidade das práticas das artes, do lugar que ocupam, do que "fazem" no que diz respeito ao comum. As práticas artísticas são "maneiras de fazer" que intervêm na distribuição geral das maneiras de fazer e nas suas relaçôes com maneiras de ser e formas de visibilidade" (RANCIÈRE, 2009. p. 17).

A Partilha do Sensível, unida ao potencial estético e formativo da arte em uma experiência conjunta e didática de leitura, parece ter potencial de proporcionar uma formação estética e crítica mais ampla a respeito da ciência e da tecnologia nos âmbitos dos sentimentos e da responsabilidade, por exemplo, no processo produtivo.

\section{Observaçóes dos Participantes Quanto a Atividade}

Finalizaremos a apresentação deste trabalho com as consideraçôes dos próprios participantes a respeito da experiência no LabHumTec.

Ao dizer sobre como a experiência do LabHumTec o ajudou a ampliar suas perspectivas, Alonso nos diz:

"Essa experiência também ajudou a ampliar minha perspectiva no que se refere a desen-
volvimento de produto. Isso de você pegar nuances, ver que os problemas sempre exis-
tiram e vão continuar a existir. Existem fatores dos quais não temos controle e as coisas
podem migrar para lugares completamente diferentes. Isso tem que ser levado em conta
quando você quer desenvolver alguma coisa."

Notemos que, segundo o colaborador, o que possibilitou a ampliação de suas perspectivas foi o fato de poder observar os debates a partir de várias "nuances" a respeito da história. Sua conclusão é de que problemas sempre existirão e assume, por fim, o limite da racionalidade humana para lidar com todos os problemas, e isso tem que ser levado em conta quando da produção e desenvolvimento de alguma soluçáo. 
Já Naoko, em sua colaboração, nos diz sobre a possibilidade de influência do LabHumTec na sua forma de pensar e refletir sobre desenvolvimento de produtos:

"Eu sei que mudou bastante coisa para mim. Eu não sei como que isso afetaria dentro daquilo que eu vou desenvolver. Mas com certeza eu acredito que essa reflexão; eu acho que tudo que a gente faz é dentro de um conjunto. Eu não consigo dizer agora que "ah, isso vai me influenciar" não sei. Porque eu ainda não comecei a fazer. Mas com certeza isso vai me afetar da mesma forma como todo contexto de vida no geral acaba afetado naquilo que a gente faz".

Importante salientar a observação da colaboradora de que, apesar de não poder afirmar que a experiência influenciaria diretamente no desenvolvimento de produto por não ter, na situação, ainda iniciado a produzir, ela afirma que a experiência certamente afeta na forma de compreender de forma mais ampla o contexto geral. Essa é uma característica da formação estética que, por sua vez, pode influenciar de forma positiva no processo produtivo, pois a reflexão sobre o mesmo possibilita uma compreensáo racional e mais ampla do contexto e, como já assinalado anteriormente, maior possibilidade de perspectivas de observaçáo do problema ao qual se deve procurar uma solução. Desta forma, entendemos ser mais uma marca do potencial de nossa atividade em gerar pensamento crítico e desenvolvimento da crítica da ciência e tecnologia.

Com o mesmo sentimento apresentado por Naoko, em sua história de vida, Nikolai também diz não poder afirmar se a experiência do LabHumTec poderia exercer alguma influência de imediato em suas atividades, mas coloca de forma veemente a importância da atividade para ampliação da sua concepção de desenvolvimento de produto de forma crítica.

"Nikolai: Também vai ser difícil dizer se a experiência no LabHum influenciou na forma como penso desenvolvimento de produto. Isso agora, porque nesse estágio do meu curso a gente não está desenvolvendo esse tipo de produto. A gente sequer está em contato direto com essas ferramentas e esses produtos da informática em saúde. Eu imagino que a visão que hoje eu tenho, a visão crítica sobre a tecnologia, e de pensar criticamente o que é que ela pode ser, como ela pode não ser aplicada de forma que não foi pensada anteriormente, eu acho que o LabHum vai me dar arcabouço para isso. Mas eu não sei dizer, porque eu nunca fiz antes. Quando eu fizer eu vou descobrir.”

E de pronto, o exemplo de uma reflexão vinda de uma obra literária gera um debate de ordem prática a respeito da tecnologia.

"Nikolai: Vou fazer um prontuário eletrônico, mas na universidade vão te falar que a enfermeira preenche ele errado. Então você já está informado que a sua criação vai se 


\begin{abstract}
“desvirtuar". Eu acho que é um pensamento mais crítico a respeito disso, porque, qual é o método errado que causa a pessoa preencher o formulário de forma errada? Eu acho que tem de entender que o formulário tem seu significado e que as pessoas vão dar valores pessoais àquilo, essas discussōes vêm. Inclusive esse exercício que se faz no LabHum facilita o processo de você conectar pensamentos que antes não estavam conectados. Com a tecnologia, por exemplo, a vingança e a maldade do ser humano, pensar que essa questáo da maldade do ser humano vai influenciar a forma como lidamos com a tecnologia.
\end{abstract}

Sentimentos e emoçóes aparecem como relevantes no processo constitutivo da racionalidade. Segundo o Filósofo Italiano Umberto Galimbert, “[...] Platão interpreta que a palavra téchne deriva de héxis noû, que significa 'ser dono da própria mente' e, portanto, daquele principio regulador da mente racional [...] (GALIMBERT, 2006, p. 42) “. A técnica aparece como reguladora da mente no âmbito do sentido atribuído ao que foi desenvolvido por meio da razão. Desta forma, a razão não somente nos constitui no ser, mas também em nosso agir, de forma que a técnica e seu significado aparecem como fruto dessa racionalidade. Portanto, entendemos que a razão tem um potencial estético, que pode influenciar no sentido atribuído à técnica que faz da tecnologia produto final dessa racionalidade. Eis a importância de pensarmos a razão de forma estética, pois é a racionalidade estética que definirá o sentido e potencial formativo da tecnologia.

\title{
Considerações finais
}

Sugerimos que nossa atividade tem o potencial de promover uma formação crítica e estética a respeito da Ciência e da Tecnologia, principalmente na área da saúde, com base na leitura de clássicos da literatura e fundamentada em nossa metodologia de leitura e discussão dos clássicos da literatura.

Quando o participante fala a respeito do potencial que nossa atividade tem de unir pensamentos antes desconectados, sugerimos o potencial do LabHumTec de promover uma reflexão crítica que, partindo das sensaçôes e da razoabilidade dos discursos e essa troca dialética em grupo, um potencial também de formação moral que cria valores referentes à racionalidade técnica e produtiva.

É com base na compreensão estética de Friedrich Schiller e os outros autores citados, que compreendemos que a arte, em nosso caso a literatura, proporciona uma formação crítica didática, a respeito da ciência e da tecnologia, pois parte de um método reproduzível, mesmo que os resultados podem ser variados. 
A metodologia didática aplicada para organização do grupo é fundamental para garantia e liberdade do participante que, em sua posse, náo fica acuado a discordar, ficando assim mais aberto a um debate democrático e de livres ideias. Nossa metodologia de pesquisa, caracterizada por ter o participante como principal fonte de análise, nos permitiu fazer uma análise conceitual mais concisa.

Por fim, unindo a teoria a metodologia referenciada, buscamos uma maneira de formar estudantes de cursos de tecnologia em saúde com uma perspectiva humanística, estética e crítica no que tange a sua atuação no mundo, levando em consideração a diversidade da vida e das formas de compreendê-la. Buscamos propor aos participantes a reflexão sobre diversas nuances da tecnologia e sua racionalidade por meio da racionalidade estética. Assim, temas como a sensação no processo criativo, moral e político, foram tratados tendo em vista que a racionalidade técnica limita, como vimos com base nos autores citados, a esfera da sensibilidade moral e ética no processo criativo e produtivo e inovador.

\section{Referências}

BITTAR, Y; SOUSA, M; GALLIAN, D. A experiência estética da literatura como meio de humanização em saúde: o Laboratório de Humanidades da Escola Paulista de Medicina, Universidade Federal de Sáo Paulo. Interface (Botucatu) [online]. 2013, vol.17, n.44, pp.171-186. BORKAN, J. Immersion/Crystallization IN: Miller W, Crabtree BF. Doing Qualitative Research. USA: Sage Publications; 1999.

DUARTE, R. Entrevistas em pesquisas qualitativas. Curitiba. Educar, Editora UFPR. 2004. n. 24, p. 213-225.

GALLIAN, D. Literatura e formação humanística em medicina: o experimento do Laboratório de Humanidades da EPM/UNIFESP. Revista de Medicina, São Paulo, v. 91, n. 3, p. 174-177, sep. 2012.

Clarett, 2017.

. A literatura coo remédio: os clássicos e a saúde da alma. São Paulo. Martin

GALIMBERT, Umberto. Psique e Techne: o homem na idade da técnica. Trad: José Maria de Almeida. São Paulo. Paulus, 2006.

GEERTZ, C. Obras e Vidas: O antropólogo como autor. Trad. Vera Ribeiro. Rio de Janeiro. Editora UFRJ. 2009.

HABERMAS, J. Técnica e ciência como “ideologia”. Trad. Felipe Gonçalves da Silva. São Paulo: Editora Unesp, 2014. 
HUXLEY, A. Literatura y ciência. Trad. Rubén Masera. Barcelona / Buenos Aires. Ed. E.D.H.A.S.A. S/d. . Admirável Mundo Novo. Trad. Felisberto Albuquerque. São Paulo. Abril Cultural, 1982.

LATOUR, Bruno. Jamais Fomos Modernos: ensaios de antropologia simétrica. Trad. Carlos Irineu da Costa. Rio de Janeiro: Editora 34, 1994.

MEIHY, J; HOLANDA, F. História Oral; como fazer, como pensar. São Paulo. Editora Contexto. 2007.

ORWELL. G. 1984. Trad: Wilson Velloso. 22 ed. São Paulo. Editora Nacional. 1991.

PEQUITO, Maria de Lurdes. O sensível e o racional: Schiller entre Kant e Hegel. IN: Educação estética e utopia política. (ORG): Leonel Ribeiro dos Santos. Lisboa. Ediçôes Colibri. 1996.

RANCIÈRE, J. A partilha do sensivel: estética e politica. Trad. Mônica Costa Netto. São Paulo: EXO experimental org.; Editora 34, 2009.

SHAKESPEARE, W. Romeu e Julieta; Hamlet, Principe da Dinamarca; Otelo, o Mouro de Veneza. Trad: F. Carlos de Almeida Cunha Medeiros e Oscar Mendes. São Paulo. Editora Abril Cultural, 1981.

SHELLEY, M. Frankenstein. Trad: Mécio Araújo Jorge Honkins. Porto Alegre. L\&PM, 2001.

SCHILlER, F. Cultura Estética e Liberdade. Org e Trad. Ricardo Barbosa. São Paulo. Hedra. 2009.

SILVA, M; GALLIAN, D; SCHOR, P. Literatura e humanização: uma experiência didática de Educação Humanística em Saúde. Rev. bras. educ. med. [online]. 2016, vol.40, n.1, pp.93-101. . Experiência didática de educação humanística em saúde. Revista Brasileira de Educação Médica, v. 40, n. 1, p. 93-101, 2016.

WELLS, H. A máquina do tempo. Trad: Braulio Tavares. Rio de Janeiro. Editora Objetiva, 2010. 


\section{Abstract}

An Aesthetic and Didactic Experience on

Science and Technology based on Literature

Introduction: This paper reflects the Aesthetic-

Formative Potential of Literature, considering the various aspects of Aesthetic Criticism of technology, which were discussed among undergraduate students of Health Technology at UNIFESP. Objectives: Our aim is to analyze the aesthetic potential of literature to think about technology. Methodology: Reading and discussions based on classics from universal literature during the meetings of the Complementary Activity, named Methodology of the Humanities and Technology Laboratory, which was offered to students of Health Technology courses at UNIFESP. For data collection, we used Participant Observation and Oral History of Life methods. The analysis was based on Hermeneutic Phenomenology. Results: Based on an Aesthetic understanding of the formation of Human Rationality, our activity seems capable of promoting the critical analysis of science and technology in various areas, both conceptual and social and productive practice. Conclusion: This research suggests the LabHumTec methodology as a way to enable an aesthetic and humanistic formation for production and technological innovation.

Keywords: Aesthetic Philosophy, Philosophy of Technology, Humanities, Science Education, Literature. 